PESHAWAR JOURNAL OF PSYCHOLOGY AND BEHAVIORAL SCIENCES, 2018, VOL. 4, NO. 2, 203-220

\title{
The Significance of Interactional Justice on Human Dignity that Shapes Mass Exodus of Employees in an Organization: A Case Study of SMEs in the Private Sector of Pakistan
}

\author{
Junaid Athar Khan ${ }^{1}$, \\ Swabi University \\ and
}

\begin{abstract}
Qadar Bakhsh Baloch ${ }^{2}$, Abdul Wali Khan University, Mardan

The study aims to investigate the relationship between perceived interactional justice and the mass exodus of employees or employee's turnover intentions in the employees of private sector Small and Medium-Sized Entities (SMEs) of Pakistan while considering the mediating impact role of human dignity/selfinterest of employees. Deductive research approach with quantitative methodology was used for conducting this study and responses from 50 employees working in 10 different SMEs located in twin-cities Rawalpindi and Islamabad were obtained through pre-structured questionnaires. Multiple regression and inter-variable correlation analysis were appliedto evaluating the relationship between the given variables of the study. SPSS data analysis tool was used for the statistical evaluation of responses obtained from the participants of the study, which were then interpreted and explained under each relevant section. The findings of this study fully supported the conceptual framework by accepting all the three hypotheses of the study including H1: Interactional Justice has a significant impact over employee's turnover intentions, H2: Human dignity/self-respect factor significantly affects employees perceptions towards interactional
\end{abstract}

\footnotetext{
${ }^{1}$ Assistant Professor (Management Science), Abdul Wali Khan University, Mardan

${ }^{2}$ Professor, Institute of Business and Leadership, Abdul Wali Khan University, Mardan
}

ISSN 2415-6779 EISSN 2518-4474

https://doi.org/10.32879/picp.2018.4.2.203

www.pjpbsicp.com 
justice and H3: Human dignity/self-respect factor significantly affects employee's turnover intentions. The mediating moderation among the selected variables was tested under the theoretical framework established by Baranowski, Anderson and Carmack, (1998). Finally, the researcher identified certain limitations related to the given evaluation and also provided explanations regarding the possible future implications of the given study, so that the future researchers can use this study as an effective pool of knowledge before starting their respective studies.

Keywords: interactional justice, human dignity, self-respect, mass exodus of employees, employees turnover intentions, SMEs in Pakistan and private sector organizations.

Since the inception of this world and the creation of mankind, human beings always tried to build an in-depth understanding of their talent and abilities to change their underlying environment, where they live or work. However, with the passage of time and globalization of the world, organizational structures became more complex day by day, which increases the concerns of individuals regarding the attitudes and approaches that their organizations extend towards them. Therefore, organizational justice and its implications over the performance of employees of an organization and its overall sustainability in the market remained a hot topic of investigation for the researchers. However, due to further development and integration of more complex practices in an organizational structure, the researchers' and management's focus of attention has been moved on towards the selfefficacy or self-dignity of employees. Bosman(2014) commented that it is the innate desire or objective of each to make his/her value or respect in a particular organization, while whenever they feel that their respect and dignity is compromised, they are not expecting to continue with such organization at any cost. Hence, the employee's turnover intention automatically increases, and the overall corporate sustainability of such organizations becomes at risk.

\section{Background of the industry}

Since the foundation of Pakistan in 1947, it excessively relied upon the private sector as a primary source for the goods and services output. However, in the late 1970s, a significant shift in national level policies of the country was observed towards the command economy and as a result 
majority of the private sector companies was acquired by the government under the policy of nationalization (Malik \& Mujtaba, 2018). Soon after this initiative, the economic growth of the country was considerably compromised, and therefore, in 2000, the newly appointed government started economic reforms with a greater focus upon generation of such economic reforms that can ensure the macroeconomic stability of the economy. These reforms include the promulgation of the Privatization act of 2000 , establishment of the ministry of investment and privatization, empowering the SBP central board for implementing and devising the country's monetary policy, the establishment of the Board of Investment and creation of the fiscal and monetary board to regulate the country's economic policies. As a result of the improved economic conditions and stability in microeconomic growth indicators, the country has privatized majority of the national level organizations, andcurrently, about $90 \%$ of the commercial banks of Pakistan are privatized (MA \& FA, 2017).

Similarly, almost $100 \%$ of the telecommunication and textile sectors along with a significant portion of the automobile, cement, services industry, sugar and fertilizers companies are privatized. As a result,some (SMEs) in each of the before mentioned industries have been emerged, which in turns increases the dependence of Pakistani economy over the private sector of the country (Khaliq, 2017). Moreover, in the financial services industry, in addition to the commercial banks, the capital market of the company have been developed at a rapid pace. Similarly, with the establishment of Pakistan Stock Exchange, it has been emerged as the most important institution for capital market formulation and recognized as the strongly performing stock markets among the emerging Asian countries/markets (Sharif, 2017).

\section{Problem Statement}

The increasing dominance of privatization in Pakistan has on one side created a high number of employment opportunities in the country and contributed effectively into the macroeconomic stability of Pakistan. Majority of the large conglomerates and multinational brands follow a complete code of good corporate governance practices with respect to their attitude and approach towards their employees. However, due to the increasing purchasing power of the general public, competition in the domestic industry is drastically increased, which in turns encouraged the local investors to start a business and as a result,a number of small and medium-sized private companies have been established in Pakistan. These companies do not follow a code of corporate governance and also lack 
proper HR policies and procedures to deal with their employees. Therefore the employees' turnover rate in such companies is significantly high. Another reason identified for the higher employees' turnover rate is that the majority of such companies are mostly under the direct supervision or control of its owners. Such owners mostlyexhibit an autocratic style of leadership and do not take into account the organizational justice factor, while dealing with his/her employees.

\section{Purpose of the Study}

The present study was aimed to establish an understanding regarding the relationship of interactional justice and employees turnover intentions in the private sector organizations of Pakistan, especially in the (SMEs) organizations. It could also evaluate the perceptions of employees regarding whether their dignity and self-respect were valued in their respective organizations or not. Similarly, it was also aimed to evaluate that how such perceptions shape their turnover intentions concerning their organizations. Human dignity played a mediating role in the given evaluation because it was an important factor that logically explained the reasons behind employees' decisions regarding continuing their employment within a particular organization. The study also helped in building an understanding regarding factors affecting human dignity or selfrespect of employees in an organization and how it could affect the interactional justice practices in such SMEs and its relationship with the employees turn over intentions. Moreover, past literature had mainly focused upon evaluation of the relationship between interactional justice and employees turnover intentions, while considering factors like organizational structure, culture and monetary/moral recognition of employees and very few studies have considered the factors like human dignity or self-respect (Başar, \&Sığrı, 2015). This study mainly focused upon the human dignity/self-respect factor that how it can affect the relationship between interactional justice and employees turnover intentions.

\section{Research Question}

In order to achieve the mentioned purpose and objectives of the given study, the researcher formulated the following main research question:

"What were the factors affecting human dignity of employees in SME firms in the private sector of Pakistan and how it shaped the 
relationship between interactional justice and employees' turnover intentions?"

The following listed sub-questions supported the researcher's investigations under the given research question for this study:

- What are the implications of interactional justice over human dignity of employees of SMEs in the private sector of Pakistan?

- What are the perceptions of employees regarding interactional justice in SMEs in the private sector of Pakistan?

- What are the implications of perceived interactional justice over the employees turn over intentions in SMEs in the private sector of Pakistan?

\section{Hypotheses}

On the basis of the given theoretical framework, the researcher has developed the following listed hypothesis:

H - 1: Interactional Justice has a significant impact on employee's turnover intentions.

H - 2: Human dignity/self-respect factor significantly affects employees' perceptions of interactional justice.

H - 3: Human dignity/self-respect factor significantly affects employees' turnover intentions.

\section{Literature Review}

\section{Interactional Justice Impact on Mass Exodus/Turnover}

Interactional justice is one of the five dimensions of organizational justice. Dai andXie, (2016) explained the term interactional justice as "the degree to which people are affected by the decisions of an organization and how they are treated with respect and dignity" (p. 58). As per this definition, interactional justice focuses on the interpersonal treatment that the members of an organization receive as an outcome of the implementation of procedures (Dai \&Xie, 2016). Mass Exodus refers to the turnover/departure of employees in a larger number from an organization or an incident in which a large group of people leaves a place at the same time (Caldas, Elkington, O’Connor \& Kim, 2015).

Otto and Mamatoglu, (2014) explained that the organizational justice regardless of its type has a great potential to influence the performance of employees in an organization. Their study further suggested 
that employees who are highly satisfied with organizational justice are usually high performers and highly committed to their organization.

Organizational justice regardless of its type has emerged as a crucial phenomenon helping in understanding the workplace behaviors and attitudes as well as its potential consequences on people (Nery, Neiva \& Mendonça, 2016; Castillo \& Fernandez, 2017; Tourani et al., 2016). Interactional justice also hasa great level of influence on the intentions of employees to leave an organization. Zagladi, Hadiwidjojo, Rahayu \& Noermijati(2015)identified six different characteristics to explain the nature of interactional justice. These characteristics include honesty, respect for individual rights, justifying decisions, avoiding deception, the dignity of behavior, and courtesy. The perception of employees regarding a particular characteristic of interactional justice affects the degree of turnover intentions.

The areas of interactional justice normally encompass employee's loyalty, theft and alienations, citizenship behavior, job satisfaction, organizational commitment, and turnover intentions (Ravangard, Ansarizade \& Sajjadnia, 2013). Başar \& Sığrı, (2015)divided interactional justice into two sub-categories: informational justice, and interpersonal justice. Informational justice demonstrates that employees are furnished with objective data and provided with a certain sensible amount of explanations, whenever there is a withdrawal from expectations. Whereas, interpersonal justice is the degree of politeness, respect, and dignity to which employees are treated in an organization. The absence of any of these forms of interactional justice results in an increase in a mass exodus. Majority of the past literature focused upon the impact of organizational justice over the overall satisfaction of employees in an organization, however, the interactional justice dimension of the organization justice is not investigatedwith respect to employee's intentions of continuing their sty or leaving an organization (Yuan, Jia \& Zhao, 2016).

\section{The Relationship between Interactional Justice and Human Dignity}

Human dignity at workplace refers to the behavior of an organization towards its people in a way that it respectfully recognizes their presence and devising such policies and procedures to enhance their individual performance and well-being. When employees are treated with high human dignity, they become high performers of the organization because only then they can experience a direct correlation between their personal goals and organizational goals (Lucas, 2015; see also Kostera \& Pirson, 2016; Kirchhoffer, 2017). 
Interactional justice has a great influence on human dignity because it is the basic way that defines how the procedures and decisions of an organization treat its people. If employees fairly perceive interactional justice in an organization, there must be high importance given to human dignity. The human dignity and interactional justice have a positive relationship because both are relatedto humanistic management of the procedures and methods of an organization (Kostera \& Pirson, 2016). Under the concept of human dignity, the focus of the management remains on those priceless things that cannot be exchanged such as emotions, happiness, selfesteem, and commitment. When organizations do have this concept, the chances of fairness in organizational justice in all of its five dimensions become high (Al-Kilani, 2017).

Organizational justice has a strong connection with people, from an individual perspective it involves the long-term interests of individuals both in terms of material and emotional aspects and also exhibits a strong association with their current and plans from the perspective of interpersonal relationship, organizational justice demand for human dignity, the degree of interpersonal relationship and status. Similarly, on the other hand from the perspective of organizational management, organizational justice demand for the positive degree of relationship between the upper and lower management, team cohesion, sustainable development, group interaction, and organizational performance. Furthermore, from the social development point of view, it exhibits a strong and positive correlation between social stability and advancement (Chunlei, 2017).

The individual perception of employees regarding the fairness of interactional justice in an organization varies from person to person due to the difference between understanding levels of the staff members. Therefore, the perception of human dignity in an organization might also differ from person to person due to its strong connection with organizational justice (Lucas, 2015).

\section{Implications of Human Dignity in an organization and its impact on Mass exodus}

Machado and Teixeira, (2017) found that human dignity has an inverse relationship with mass exodus/employee turnover. When an organization practice human dignity fairly the degree of mass exodus will be relatively lower because of the commitment level and job satisfaction among employees will be high. Similarly, the lower level of human dignity in an 
organization can cause higher chances of a mass exodus due to high job dissatisfaction and lower organizational commitment among employees.

Organizations that are violating the rights and policies of human dignity are raising questions related to the fairness of the level of organizational justice and also affecting the degree of job satisfaction, citizenship behavior, organizational commitment, and employee self-esteem and self-efficacy. The prevalence of such practices in an organization causes negative impact over the level of human dignity and also negatively affects the employee's motivation level at the workplace, which in turns lower down their job satisfaction and commitment in the long run. Furthermore, it also causes a negative perception of organizational justice among its employees and adversely affects the organizational citizenship behavior, which in turns increases the turnover intentions among its employees (Lucas, 2015). Sharif (2017) suggested that to avoid a mass exodus, human dignity in an organization should be "respected, protected, and promoted" (p. 95). He further explained that dignity in an organizational setting is not the responsibility of the management alone, and this is the thing that people usually perceive wrongly. Every member of an organization should respect, protect and promote the dignity of others to create a positive and fair organizational culture.

Bosman (2014) has also found the negative relationship between human dignity in an organization and mass exodus because according to him the status of human dignity in an organization works as a foundation to the fair and just distribution of financial and socio-emotional rewards.

\section{Conceptual Framework}

The concept of mediated moderation has been used for developing a hypothesis to test the given variables of the study. This concept will help in evaluating whether the factor of self-respect and dignity of employees mediates the impact of interactional justice over the turnover intentions of employees. The impact of mediating moderation in the given study among the selected variables will be tested under the theoretical framework

established by Baranowski, Anderson and Carmack, (1998), the graphical representation of the theoretical framework is given as under: 


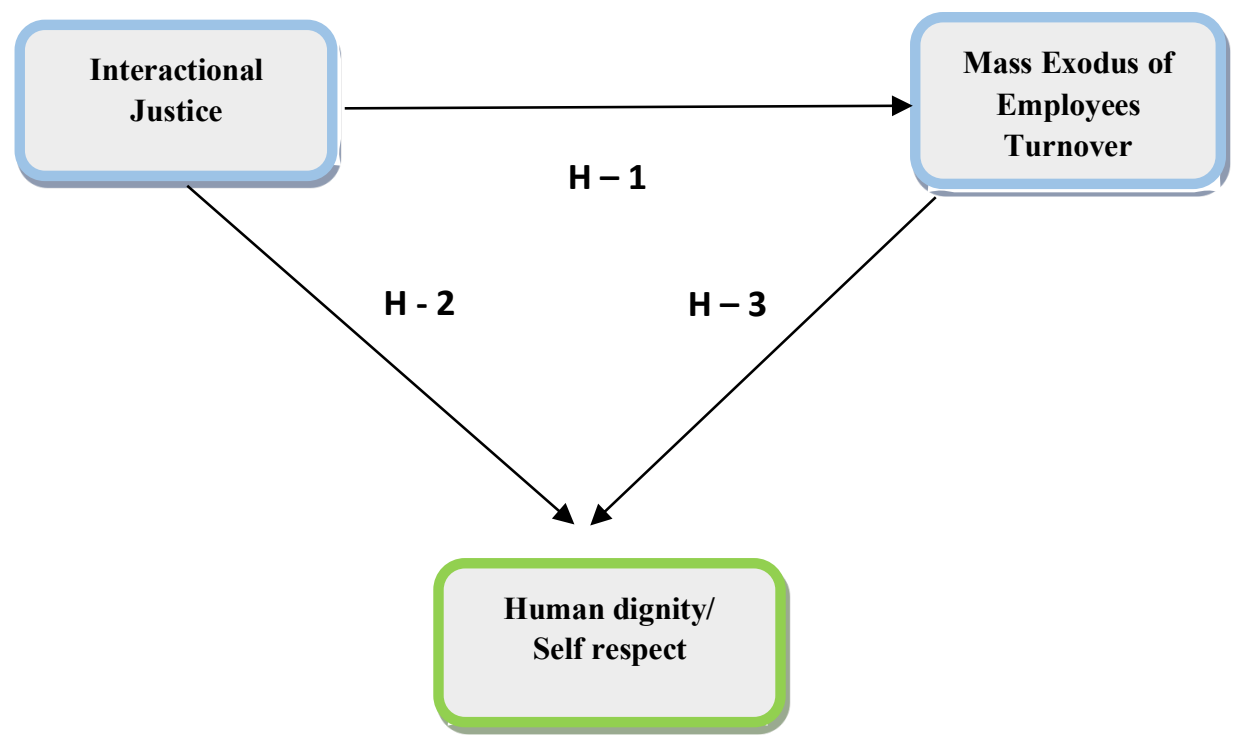

Figure -1 : The model is showing the relationship between interactional justice and employee's turnover intentions that is mediated by the Human Dignity Factor.

\section{Method}

The researcher has adopted a deductive approach for conducting this study because it is the most appropriate research approach for the investigation of the cause and effect relationship between the given variables.

\section{Research Design}

The researcher has adopted a quantitative research design for conducting this study and used the theoretical framework of Baranowski, Anderson and Carmack, (1998) to investigate the cause-effect relationship between the given variables of the study. Moreover, for the collection of quantitative data, the researcher has used pre-structured questionnaires that contain information regarding all the variables of the study and collection of data regarding the demographic characteristics of the participants.

\section{Sampling Procedures}

Population for this study is all the SMEs of private sector industry of Pakistan, while for the convenience of the researcher and practically 
execution of the study, the researcher has selected a representative sample of 10 companies from Rawalpindi and Islamabad that fall into the definition of Small and Medium Sized companies. The selection of these companies was made by a list of Small and Medium Sized Companies on the SECP website on a random basis, while a representative sample of 50 employees from these companies was selected and questionnaires were distributed among these participants through personal reference and social media communication channels.

\section{Data Collection Instruments}

The researcher used Pre-structured questionnaires for the collection of data from the target participants of the study, the questionnaire consists of two parts, the $1^{\text {st }}$ part was developed for seeking demographic information from the participants. While the second part contained 11 questions that were aimed to obtain responses from the participants regarding the given variables of the study, i.e., human dignity/self-respect of employees, interactional justice in the organization and employees turnover intentions.For the purpose of measuring responses of the participants, the researcher had established a 5 point Likert scale chart ranging from $1=$ strongly disagree to $5=$ strongly agree.

\section{Data Analysis and Discussion}

SPSS data analysis tool is used for the evaluation of the responses that are collected from the participants of the study to investigate the possible relationship between interactional justice and employees turnover intentions while taking into consideration the mediating role of human dignity/selfrespect of the selected participants. SPSS provided results regarding tvalues, frequencies, correlations, mean values, standard deviations and helped the researcher in conducting multiple regression analysis. Reliability testing was also performed for increasing effectiveness of the items provided in the questionnaires. Items having more than 0.70 value of Cronbach's Alpha were considered reliable, while those having less value were eliminated from the final questionnaire (Table -1$)$. The researcher had used independent sample t-test, one-way ANOVA, one sample t-test and applied

multiple regression and correlation analysis for identifying/explaining possible relationships between the given variables of the study. 
Table 1

Reliability Measurement

\begin{tabular}{lcc}
\hline \multicolumn{1}{c}{ Variables } & $\begin{array}{c}\text { Factor } \\
\text { Loading }\end{array}$ & $\begin{array}{c}\text { Cronbach's } \\
\text { Alpha }\end{array}$ \\
\hline $\begin{array}{l}\text { Interactional Justice } \\
\text { When decisions are made about my job, my }\end{array}$ & .58 & 0.82 \\
supervisor treats me with kindness and & & \\
consideration? & .71 \\
When decisions are made about my job, my & & \\
supervisor truthfully treats me? & .82 \\
Concerning decisions made about my job, my & & \\
supervisor usually discusses the expected & & \\
impacts of the decisions with me? & & \\
My supervisor explains clearly any decision if it & .78 \\
is related to my job? & & \\
When decisions are made about my job, my & .39 \\
supervisor shows concerns for my rights as an \\
employee?
\end{tabular}

PESHAWAR JOURNAL OF PSYCHOLOGY AND BEHAVIORAL SCIENCES, 2018, VOL. 4, NO. 2, 203-220 
Table 1 shows that all those items were included in the questionnaires that reported Cronbach's Alpha loading of 0.7 or above. Hence, the given table shows that the final questionnaire of the study contained three items for interactional justice variable, fouritems for employee's turnover intentions and threeitems for human dignity/selfrespect of employees. Moreover, the researcher had taken the mean value of more than three as a qualifying indicator for assessing the high consciousness of employees towards factors like human dignity and selfrespect.

Table 2

Demographic Evaluation of the Respondents

\begin{tabular}{llccc}
\hline \multicolumn{1}{c}{ Variable } & \multicolumn{1}{c}{ Category } & Frequency & Percent & $\begin{array}{c}\text { Cumulative } \\
\text { Percentage }\end{array}$ \\
\hline Gender & Male & 30 & 60 & 60 \\
& Female & 20 & 40 & 100 \\
Age & $20-30$ & 35 & 70 & 70 \\
& $30-40$ & 5 & 10 & 80 \\
& $40-50$ & 5 & 10 & 90 \\
Education & above 50 & 5 & 10 & 100 \\
Level & Illiterate & 0 & 0 & 0 \\
& high school & 12 & 24 & 24 \\
& graduates & 25 & 50 & 74 \\
Occupation & postgraduates & 13 & 26 & 100 \\
& Operational & & & \\
& Level & 30 & 60 & 60 \\
& Tactical Level & 12 & 24 & 84 \\
& Strategic Level & 8 & 16 & 100 \\
\hline
\end{tabular}

Attribution of the highest number of respondents to that particular group is due to the fact thatmostly fresh graduates join private sector organizations at the startup of their career because they do not find any suitable public sector job at that instance of time due to the prevailing high unemployment rate in the country. With respect to education, the highest number of respondents fell into the graduates' category for the same reason as stated above in connection with the age group. Regarding the occupational level majority of the operational level employees responded to the questionnaire because the mass exodus of employees usually occurs at this level of the private SMEs organizations. 
Table3

Inter-variable Correlation

\begin{tabular}{lcccc}
\hline \multicolumn{1}{c}{ Variables } & Mean & $\begin{array}{c}\text { Standard } \\
\text { Deviation }\end{array}$ & IJ & HD \\
\hline Interactional Justice & 3.060 & 1.349 & & \\
$\begin{array}{l}\text { Human Dignity / Self } \\
\text { Respect of Employees }\end{array}$ & 3.085 & 1.204 & $0.783^{* *}$ & \\
$\begin{array}{l}\text { Employees Turnover } \\
\text { Intentions/ Mass }\end{array}$ & 3.437 & 1.231 & $0.740^{* *}$ & $0.791^{* *}$ \\
Exodus of Employees & & & & \\
\hline
\end{tabular}

**. Significance level of $<0.01$ (2-tailed).

The table 3 shows the inter-variable correlation analysis for evaluating the relationship between independent and dependent variables of the given study: Results in the given table show that human dignity or employees 'self-respect plays a vital role in establishing a relationship between interactional justice and employees turnover intentions or a mass exodus of employees in private sector SMEs of Pakistan, i.e. $(\mathrm{P}<0.01)$, hence all the given three hypotheses of the study are supported. This further evaluates that if employees are feeling respectful, or their dignity is not compromised in an organization, then they feel motivated and satisfied with their workplace. Because the majority of the employees were of the viewpoint that they are struggling only to earn a respectful life in their communities. Therefore, if someone even their bosses gets personal or target their dignity, they won't go to continue their jobs at such organizations.

Table 4

Multiple regression Analysis

\begin{tabular}{lccccc}
\hline & $\begin{array}{c}\text { Unstandardized } \\
\text { Coefficients }\end{array}$ & $\begin{array}{c}\text { Standardized } \\
\text { Coefficients }\end{array}$ & & \\
& B & Std. Error & Beta & t & Sig. \\
\hline (Constant) & 2.603 & .41 & & 5.39 & .001 \\
\hline
\end{tabular}




\begin{tabular}{llllll}
\hline HD & .417 & .10 & .43 & 4.41 & .001 \\
ETI & .283 & .17 & .26 & 3.42 & .001 \\
\hline
\end{tabular}

Adjusted R Square $=0.463$

Table 4 shows multiple regression analysis to confirm the evaluations obtained by correlation analysis regarding the validity of the given hypothesis of the study. The following table -4 shows the results of multiple regression analysis, the evaluations of this analysis tool showed that there is a significant positive relationship between the interactional justice and employee's turnover intentions in an organization. It also confirms the mediating role of Human dignity or self-respect of employees in defining such relationship, i.e. $(\mathrm{P}<0.01)$ hence accepting all the three hypotheses of the study. Moreover, the independent variable Interactional Justice can cause $46.3 \%$ variations in the dependent variables, which shows that a unit change in an independent variable can cause a considerable level of corresponding change in the dependent variable.

\section{Conclusion}

The current study had performed investigation over evaluation of the relationship between interactional justice and the mass exodus of employees/turnover intentions of employees while considering the mediating role of human dignity or self-respect of employees in SMEs in private sector of Pakistan. For the given purpose, the researcher considers one main question and three sub-questions, which were highly aligned with the objectives and hypothesis of the study. The findings of statistical analysis showed that all the three hypotheses of the study supported the relationship between interactional justice and employees turnover intentions and hence accepting all the three hypotheses. The researcher also concluded that human dignity was an important factor especially with respect to the psychological and social background of Pakistani employees, who are comparatively more emotional. Employees mostly responded that they would never compromise over their self-respect and dignity in an organization, while in SMEs majority of the owners were also working as directors or managers of the company and had a direct relationship with the employees. Therefore they imposed direct influence over their employees and most of the time start controlling them like slaves. 
Similarly, the salaries in these organizations were also quite low and unjustifiable against the extent of work; employees were required to perform. Hence, this in turns negatively affects their motivation level and sometimes affects their innerself-respect and dignity, which in turn caused a mass exodus from such an organization. Another reason behind mass exodus is that there were very limited numbers of employees in such SMEs, so they usually had strong ties and emotional bonds with one another, so whenever an employee became a victim of any sort of insulting behavior of his/her employer, the other employee left the organization to record their protest.

\section{Limitation and future recommendations}

This study has focused upon the impact of interactional justice over employees turnover intentions in SMEs in the private sector of Pakistan only. Therefore, the findings of this study may not be applicable or valid over the employees or private sector organizations of developed countries. Similarly, the study has based its evaluations on an emotional state of mind or characteristic of an individual. Therefore, the societal norms and priorities changes with a change in culture and religion, hence the findings of this study may also not be valid or applicable over the residents of other ethnicities or regions of the world. Moreover, the researcher has selected very few numbers of SMEs within a limited geographical jurisdiction. Therefore the generalizability of this study might be affected due to the fact that employees in other cities of Pakistan might have different emotional state of mind. For example, the cultural values and emotional state of individuals belong to Pukhtoon ethnicity is quite different from that of other ethnicities residing in the country, like Baloch, Punjabi, and Shindi.

However, this study has a considerable significance it laid down a building block for the researchers to conduct study into their perspective and implication of interactional justice over employees of an organization. Similarly, it has provided useful information with logical evaluations to the employers in the private sector organization to reduce down the increasing employee's turnover in their organizations by establishing certain effective policy measures. The findings of this study would also help the public sector executives and policymakers to look to establish such policies and procedures that could ensure effective provision of interactional justice to lower level employees so that they could feel themselves as an integral part of their respective organizations. So the implications of this study might give different results even in other regions within Pakistan. The future researcher can use this study as a valuable piece of information regarding this new 
aspect of the emotional state of mind of individuals that could affect the relationship between interactional justice and employee's turnover intentions. Similarly, it is also recommended that the findings of this study would provide the conceptual background and basis for the future researchers to conduct investigations over the given topic and provide logical assessments to both the corporate and private sector organizations. The study also recommends the corporate sector employees to adopt certain revamped policies and procedures for the effective running of their respective organizations in the long run.

\section{References}

Abdul Khaliq, C. (2017). Knowledge Management Practices and Organizational Performance of SMEs in Pakistan. Business \& Economic Review, 9(3), 173-183. doi: 10.22547/ber/9.3.7

Al-Kilani, M. (2017). The Influence of Organizational Justice on Intention to Leave: Examining the Mediating Role of Organizational Commitment and Job Satisfaction. Journal of Management and Strategy, 8(1), 18. http://dx.doi.org/10.5430/jms.v8n1p18

Baranowski, T., Anderson, C., \& Carmack, C. (1998). Mediating variable framework in physical activity interventions. American Journal Of Preventive Medicine, 15(4), 266-297. doi: 10.1016/s07493797(98)00080-4

Başar, U., \&Sı̆grı, Ü. (2015). Effects of Teachers' Organizational Justice Perceptions on Intention to Quit: Mediation Role of Organizational Identification. Educational Sciences: Theory \& Practice, 45-59. doi: 10.12738/estp.2015.1.2326

Bosman, H. (2014). The Exodus as negotiation of identity and human dignity between memory and myth. HTS Teologiese Studies / Theological Studies, 70(1). doi: 10.4102/hts.v70i1.2709

Caldas, C., Elkington, R., O’Connor, J., \& Kim, J. (2015). Development of a Method to Retain Experiential Knowledge in Capital Projects Organizations. Journal Of Management In Engineering, 31(5), 04014083. doi: 10.1061/(asce)me.1943-5479.0000322

Castillo, C., \& Fernandez, V. (2017). Relationships between the dimensions of organizational justice and students' satisfaction in university contexts.

Chunlei, Z. (2017). Research on the Effect of Organizational Justice on Human Resource Management. Advances in Economics, Business and Management Research, 48. 
Dai, L., \& Xie, H. (2016). Review and Prospect on Interactional Justice. Open Journal Of Social Sciences, 04(01), 55-61. doi: $10.4236 /$ jss.2016.41007

Kirchhoffer, D. (2017). Human Dignity and Human Enhancement: A Multidimensional Approach. Bioethics, 31(5), 375-383. http://dx.doi.org/10.1111/bioe.12343

Kostera, M., \& Pirson, M. (2016). Dignity and the organization.

Kulkami, V. (2011). Mass Exodus of Workers: A Case of Strike in Power Loom Industry in Surat. SSRN Electronic Journal. http://dx.doi.org/10.2139/ssrn.1857405

Lucas, K. (2015). Workplace Dignity: Communicating Inherent, Earned, and Remediated Dignity. Journal Of Management Studies, 52(5), 621-646. doi: 10.1111/joms. 12133

MA, S., \& FA, S. (2017). Uncovering Key Performance Indicators for Private Sector Banks in Pakistan: An Application of Exploratory Factor Analysis. Journal Of Business \& Financial Affairs, 06(01). doi: 10.4172/2167-0234.1000248

Machado, M., \& teixeirA, M. (2017). Dignity in the Context of Organizations: A Look Beyond Modernity.

Malik, M., \& Mujtaba, M. (2018). Impact of E-Recruitment on Effectiveness of HR Department in Private Sector of Pakistan. International Journal Of Human Resource Studies, 8(2), 80. doi: 10.5296/ijhrs.v8i2.12869

Nery, V., Neiva, E., \& Mendonça, H. (2016). The Changing Context and the Organizational Justice Impact on the Employee Well-Being.

Otto, K., \& Mamatoglu, N. (2014). Why Does Interactional Justice Promote Organizational Loyalty, Job Performance, and Prevent Mental Impairment? The Role of Social Support and Social Stressors. The Journal Of Psychology, 149(2), 193-218. doi: 10.1080/00223980.2013.866535

Ravangard, R., Ansarizade, N., \& Sajjadnia, Z. (2013). Study of the effects of perceived organizational justice and its components on organizational commitment of administrative and financial employees of Shiraz University of Medical Sciences general hospitals in 2012. Archives Of Pharmacy Practice, 4(1), 35. doi: 10.4103/2045080x.111580

Saxena, S., \& Muhammad, I. (2018). Barriers to use open government data in private sector and NGOs in Pakistan. Information Discovery And Delivery, 46(1), 67-75. doi: 10.1108/idd-05-2017-0049 
Sharif, S. (2017). From Mutualized Exchange to Investor-Owned Demutualized Entity: The Case of Pakistan Stock Exchange. SSRN Electronic Journal. doi: 10.2139/ssrn.3016245

Tourani, S., Khosravizadeh, O., Omrani, A., Sokhanvar, M., Kakemam, E., \& Najafi, a. (2016). The Relationship between Organizational Justice and Turnover intention of Hospital Nurses in Iran. Materia Socio Medica, 28(3), 205. doi: 10.5455/msm.2016.28.205-209

Yuan, G., Jia, L., \& Zhao, J. (2016). Organizational identification moderates the impact of organizational justice on job satisfaction. Work, 54(1), 189-195. doi: 10.3233/wor-162271

Zagladi, A., Hadiwidjojo, D., Rahayu, M., \&Noermijati. (2015). The Role of Job Satisfaction and Power Distance in Determining the Influence of Organizational Justice Toward the Turnover Intention. Procedia Social And Behavioral Sciences, 211, 42-48. doi: 10.1016/j.sbspro.2015.11.007 